\title{
Planejando aulas de botânica a partir de uma provocação
}

Renata Carmo-Oliveira

Daniela Franco Carvalho

\section{Resumo}

Esse texto aborda o desenvolvimento de uma ação na disciplina de Estágio Supervisionado em Biologia na tentativa de compreender o que poderia estimular futuros professores a planejarem aulas interativas na temática da Botânica para o Ensino Médio, tendo como base um roteiro confeccionado a partir do modelo de design pedagógico e dos recursos didáticos botânicos que estavam dispostos em quatro estações sobre as bancadas do Laboratório de Ensino de Ciências e Biologia. A coleta de dados ocorreu por meio da metodologia da observação discreta. As estações provocaram comportamentos e interesses distintos nos licenciandos, levando-os a se dirigirem primeiramente às estações com o material vivo ou fresco. Foi possível observar dificuldades em todos os grupos, independentemente do tipo do material, para a elaboração dos planejamentos de aula. A partir dos dados discutimos a proposta de provocação relacionada à criatividade e autonomia do professor.

Palavras-chave: formação inicial de professores, botânica, criatividade.

\section{Abstract}

\section{Planning botanical classes through a provocation subject}

This article addresses the development of an action in the subject of Internship in biology of Biological Sciences Course at the Federal University of Uberlândia (UFU), Brazil, in trying to understand what could stimulate future teachers of biology to plan interactive lessons about Botany. Students were asked to form groups to work out a plan for Botany classes in high school, based on a made script from the pedagogical design model and botanical teaching resources that were arranged in four stations on Science and Biology Education laboratory countertops. Data collection occurred through the discreet observation methodology. The stations caused behaviors and different interests in undergraduates, leading them to firstly directing to live or fresh material. We observed difficulties in all groups, regardless of the type of botanical teaching resources, for the preparation of lesson plans. From the data discussed the proposal of provocation related to creativity and autonomy of teachers.

Keywords: teacher education, botany, creativity. 


\section{Introdução}

Como professoras da área de Prática de Ensino do Curso de Ciências Biológicas da Universidade Federal de Uberlândia (UFU) temos nos deparado com alguns dilemas sobre a formação de futuros professores de Ciências e Biologia semestre após semestre.

Na disciplina de Estágio supervisionado em Biologia, ofertada no último período do curso, logo nos primeiros encontros fica evidenciada uma ansiedade coletiva nos licenciandos de ir para a regência, de estar na escola, de fazer. Por já terem experimentado a docência para o ensino fundamental, no Estágio supervisionado em Ciências, e desenvolvido diferentes atividades em escolas durante o curso, se sentem prontos para o serviço docente. Como traço marcante nossos alunos acreditam que uma boa aula é aquela que tem como preceito o conteúdo. Quando colocamos que é preciso planejar o estágio, entender as diferentes percepções sobre o fazer docente, estudar, vivenciar a escola, estabelecer uma parceria com o professor regente, compreender a dinâmica da sala de aula e estruturar as atividades para a sequência de conteúdos a ser desenvolvida, além de muita reclamação, temos nos deparado com posturas que muito se assemelham as que os próprios licenciandos rechaçam nos estudantes da Educação Básica: descompromisso, indisciplina, atrasos, ausências, intolerância e indiferença. Buscamos transpor esses desafios de forma a envolvê-los constantemente em diálogos e em diferentes reflexões sobre o se tornar professor.

No entanto, para além da dificuldade intrínseca de mobilizar discussões no momento de conclusão do curso com licenciandos que muitas vezes ainda não se decidiram pelo caminho da docência, mas que precisam atuar na regência de uma sala de aula pois se matricularam em estágio, está a barreira do conteúdo. Geralmente há uma expectativa inicial de que venham a ministrar conteúdos de Zoologia, Evolução, Genética... mas nunca de Botânica. Tal qual na escola. O que temos acompanhado como orientadoras de estágio, nas escolas campo de estágio, é que ao planejar o conteúdo para o segundo ano do Ensino Médio, no tópico Diversidade Biológica, o professor deixa o tema Biologia Vegetal para o final, o comprometendo pelo pouco tempo disponível. A exceção está na fotossíntese, que em função do ENEM e dos vestibulares acaba sendo abordada de alguma forma no Ensino Médio.

No ensino de botânica, apesar de ser uma área bem próxima do cotidiano das pessoas, presente na alimentação e medicamentos, por exemplo, é possível perceber o distanciamento entre o que é ensinado e a realidade dos estudantes devido ao enfoque descritivo e sistemático (GARCIA, 2000).

No entanto, esse receio e até um distanciamento da Botânica (KINOSHITA et al., 2006) não é exclusivo dos licenciandos e dos professores em exercício. Mesmo em diferentes espaços educativos, como os museus de ciências, há pouca oferta de atividades que divulguem ou promovam o interesse pelas plantas, apesar de uma crescente busca por artefatos museais 
interativos com o público visitante. Emprestamos a definição de artefato de Ferreira (2014) que abarca as teorizações dos autores McLean (1993, p. 93 apud FALCÃO et al., 2003, p. 190), Nascimento e Ventura (2001), Abbagnano (2007), sendo entendido como um objeto produzido pela criação humana, projetado segundo os princípios da interatividade e com a função de divulgar conhecimento científico na exposição de um museu de ciências.

Acreditamos que é possível potencializarmos uma aula através da abordagem de conteúdos de Ciências e Biologia pela interação do estudante com o objeto. Essa interatividade pode ser material ou virtual, desde que haja contato e exploração sensorial do objeto. Adotaremos a definição de Wagensberg (2000) sobre os três níveis de interatividade: hands on (tátil - relativa à percepção sensorial do objeto, seja através do toque, da contemplação, da audição ou olfato), minds on (mental - relativa à produção de questionamentos e ampliação de repertório a partir da experiência tátil com o objeto) e heart on (emoção cultural - relativa à fruição e ao bem estar oriundo da experiência tátil e mental com o objeto).

$\mathrm{Na}$ tentativa de compreender o que poderia estimular futuros professores de Biologia a planejarem aulas interativas na temática da Botânica, estruturamos uma provocação na disciplina de Estágio. Entendemos como provocação tudo que possa estimular, possibilitar um deslocamento daquilo que nos é confortável.

Buscamos investigar se os licenciandos de um Curso de Ciências Biológicas podem ser provocados a elaborarem planejamentos inovadores de aulas de Botânica tendo recursos didáticos nessa temática como elementos mobilizadores. Assim, partimos da centralidade no objeto (recurso botânico) para provocar uma inversão na estrutura base do planejamento de uma aula.

\section{Delineamento Metodológico}

Como parte integrante da disciplina de Estágio supervisionado em Biologia do Curso de Ciências Biológicas da Universidade Federal de Uberlândia (UFU) há uma etapa em que os licenciandos são estimulados a refletirem acerca do planejamento de suas aulas na escola campo de estágio durante o período de regência.

Em função da sequência de aulas de Biologia que fora acordada na escola com a temática da Botânica, desenvolvemos com os licenciandos um exercício para estruturar o planejamento das aulas a partir de uma provocação.

Estamos conceituando essa estratégia como provocação pois os licenciandos adentraram o Laboratório de Ensino de Ciências e Biologia (LEN) e se depararam com quatro estações montadas, sobre as bancadas, com recursos didáticos botânicos distintos: 
Estação 1 (Plantas e Plântulas) - um vaso com Impatiens sp. florido, algumas plântulas coletadas no jardim do Instituto de Biologia da UFU e uma variedade de folhas;

Estação 2 (Recortes de revistas) - recortes de revistas com imagens de plantas e partes de plantas, como flores, frutos e sementes.

Estação 3 (Xiloteca) - coleção de amostras de madeira que compõem uma pequena xiloteca ilustrando diversas plantas da flora brasileira, laminário histológico de partes vegetais, lupas manuais, microscópios ópticos de luz e esteroscópicos;

Estação 4 (Jarro de flores) - ramos de diferentes plantas com flores (quaresmeira Tibouchina sp., dente de leão - Taraxacum sp. e ipê de jardim - Tecoma stans), coleção de frutos secos, terrário didático com amostras de briófitas e pteridófitas, lupas de mão e pinças.

Os catorze licenciandos se distribuíram de forma aleatória nas bancadas, compondo grupos com quatro integrantes na Estação 1, três na Estação 2, três na Estação 3 e quatro na Estação 4. Após se acomodarem, foram convidados a estruturarem propostas de planejamento para aulas de Botânica para o Ensino Médio, tendo como base um roteiro confeccionado a partir do modelo de design pedagógico proposto pela Rede Internacional Virtual de Educação (RIVED).

O roteiro englobou os seguintes itens:

- Escolha dos objetivos - O que o estudante para o qual você está planejando essa aula acharia de interessante nesse tópico?

- Escopo da aula - O que será abordado na aula? O que você quer que os estudantes vivenciem nessa aula? O que os estudantes deverão ser capazes de fazer/argumentar após essa aula? Entendemos como argumentação aquilo que ocorre pela mediação de conhecimentos (CAJAL, 2003).

Abordagem - Quais exemplos podem ser utilizados para engajar os estudantes nessa temática? 0 que pode ser interativo nesse tópico, entendendo como interativo aquilo que estimula uma relação do público com o objeto (WAGENSBERG, 2000)?

- Quais aplicações do mundo real requerem conhecimentos dessa temática? O que tem sido realizado de pesquisas nessa temática?

- Desenvolvimento da aula - Como você pretende ensinar os estudantes os conteúdos dessa temática? O que você considera importante que os estudantes façam para aprender esse conteúdo? Quais estratégias e atividades você utilizará para alcançar o objetivo proposto? Em quais etapas da aula serão necessários recursos didáticos? Quais recursos didáticos serão úteis para o desenvolvimento do conteúdo?

Juntamente com o roteiro, os licenciandos receberam uma sequência de informações e questionamentos, destacada abaixo, para considerarem no planejamento das atividades, tendo como pressuposto a busca pela interatividade nas aulas de Biologia no Ensino Médio.

R. B. E. C. T., vol 8, núm. 4, set-dez.2015 ISSN - 1982-873X

DOI: Em andamento. 
Pensando as atividades

1) Considere as ideias que você estruturou até agora e proponha atividades que gostaria que o estudante fizesse. Comece a escrever alguns detalhes sobre o que você quer que os estudantes façam para interagir com os conteúdos propostos na aula.

2) Considere três ou quatro conceitos e reflita se a atividade pode ser reconfigurada num contexto diferente.

3) As atividades permitem que sejam exploradas para além das fronteiras de suas ideias originais? Ou os estudantes estão confinados a um caminho pré-determinado?

4) Como as atividades devem ser conduzidas e organizadas?

5) Como os estudantes serão motivados a realizarem as atividades?

6) Como os resultados das atividades serão avaliados? proposta?

7) Quais as questões para reflexão, intrigantes e provocativas que se aplicam a cada atividade

8) Quais benefícios as atividades propostas trarão para os estudantes em oposição às aulas tradicionais?

9) Quem mais poderia se interessar pelas atividades propostas?

A coleta de dados ocorreu por meio de observação discreta (STUDART, 2005) dos modos pelos quais os licenciandos interagiram com os recursos botânicos durante as três horas e meia disponíveis para a estruturação do planejamento. As observações discretas forneceram os dados relativos ao comportamento dos licenciandos diante dos recursos botânicos, considerando algumas variáveis comportamentais propostas por Studart (2005, p. 59): composição do grupo; tempo gasto no módulo interativo dos recursos botânicos composto pelas quatro estações; tipos de conversa - 'dizer o que fazer', 'bate-papo' e 'explicação'.

Os planejamentos de cada grupo, respectivos aos recursos botânicos disponíveis em cada estação foram analisados tendo como base o método da análise do conteúdo (BARDIN, 1977). Moraes (1999), apresenta esta técnica de pesquisa como uma metodologia usada para descrever e interpretar o conteúdo de toda classe de documentos e textos, conduzindo a descrições sistemáticas, qualitativas ou quantitativas, ajudando a interpretar as mensagens, atingindo uma compreensão de seus significados além da leitura comum. Oliveira e colaboradores (2003) afirmam que a análise de conteúdo desenvolve um arcabouço formal para a sistematização de atributos qualitativos, e na interpretação dos dados coletados se dá o entrelaçamento da pesquisa em educação com a análise de conteúdo.

A pesquisa se configura através de uma triangulação de dados (LÜDKE e ANDRÉ, 1986) entre a observação discreta e a análise do conteúdo dos planejamentos elaborados pelos licenciandos. A conceituação de interatividade é o pressuposto teórico-metodológico para a análise dada a riqueza conceitual tanto para analisarmos as interações estabelecidas entre os 
licenciandos e os recursos botânicos como os planejamentos de aula, cuja provocação teve como base a formulação de atividades diferentes das tradicionais buscando-se a interação com o objeto.

\title{
A planta como desconhecido
}

\author{
Nove horas. Pontual, \\ estende-se no quintal \\ um tecido vegetal \\ de finos raios de sol.
}

(Nove Horas - Paulo Robson de Souza1)

As estações provocaram comportamentos e interesses distintos nos licenciandos, levandoos a se dirigirem primeiramente às estações com o material vivo ou fresco (Estações 1 e 4).

Foi possível observar dificuldades em todos os grupos, independentemente do tipo do material, mediante as quatro estações de recursos botânicos ofertados: dificuldade com a argumentação, dificuldade para interagirem com o conteúdo de botânica, dificuldade para se desprenderem da visão de ensino taxonômico, tradicional e nomenclatural, e dificuldades em pensar o ensino de botânica pelo enfoque do desenvolvimento do organismo.

Os licenciandos que se depararam com as figuras de revistas, manifestaram um descontentamento associado a uma percepção de baixo potencial pedagógico oferecido por "imagens em um papel". Aqueles que tinham em sua mesa flores e objetos ópticos não chegaram a tirar os ramos do recipiente com água e nem mesmo utilizaram as lupas de mão para verificarem detalhes ou, ainda, para "brincarem com os objetos" simulando o que um aluno da educação básica faria ao receber um material para estudarem.

Essas dificuldades, impactaram as propostas de planejamento das aulas, uma vez que se tornaram fatores limitantes da criatividade e da ousadia para a proposição de atividades inovadoras. Apesar de fazerem parte do seu conhecimento a inibição dos licenciandos frente ao recurso botânico se assemelha aos visitantes de museus, que de antemão já estabelecem para si mesmos a impossibilidade do toque, o que restringe a interatividade à contemplação visual (FALK, 2009), o que é limitante, visto que o objeto poderia ser explorado em múltiplas vertentes. Para o futuro professor essa ausência de impulso para a ampla observação e exploração do objeto nos chama a atenção, pois se o licenciando não percebe o recurso didático como provocador e estimulante para si, como conseguirá despertar o interesse nos estudantes da educação básica

${ }^{1}$ SOUZA, Paulo Robson de. Síntese de Poesia. Campo Grande: Editora UFMS, 2006.

R. B. E. C. T., vol 8, núm. 4, set-dez.2015 ISSN - 1982-873X

DOI: Em andamento. 
que estão mergulhados em um mundo real e tecnológico muito mais vibrante que os conteúdos que veiculamos através do giz e da lousa?

Para nós essa situação remete às palavras de Schön de que

"se o professor quiser familiarizar-se com este tipo de saber (saber escolar), tem de lhe prestar atenção, ser curioso, ouvi-lo, surpreender-se, e atuar como uma espécie de detetive que procura descobrir as razões que levam as crianças a dizer certas coisas. Esse tipo de professor se esforça por ir ao encontro do aluno e entender o seu próprio processo de conhecimento, ajudando-o a articular $o$ seu conhecimento-na-ação com o saber escolar" (SCHÖN, 1997, p. 82).

Outro ponto observado foi a dificuldade dos grupos frente ao modelo de planejamento design pedagógico - proposto. Os licenciandos manifestaram, por comentários, o descontentamento com o número de aspectos a serem considerados, a dificuldade em se colocarem como alunos, a refletirem sobre o que ensinar e o que se espera que o aluno aprenda. A desmotivação dos futuros professores nos levou a questionar ao longo de toda a proposta sobre os elementos necessários à criatividade docente, tendo em vista que segundo Mourão e Martínez (2006), é importante que a subjetivação das próprias ações gere emoções que animem a necessidade de criar do professor, como o entusiasmo diante do processo criativo, a excitação diante do desafio, a satisfação e sensação de auto-realização.

Para Alencar (2002), embora os anos de formação universitária, tanto de graduação como de pós-graduação, sejam da maior relevância em prover condições para que os estudantes se tornem conscientes de suas habilidades criativas e aprendam a fazer um uso maior de suas potencialidades criativas, muito pouca atenção tem sido dada ao desenvolvimento e cultivo das habilidades criativas no contexto universitário da maior parte dos países.

Nesse sentido, podemos pensar que a falta de contato com elementos provocativos dessa criatividade também possa ser um fator de constrangimento e inibição dos licenciandos.

Passamos agora à descrição do que cada grupo elaborou como proposta didática a partir do que estava disponível em cada estação.

\section{Estação 1 (Plantas e Plântulas)}

A temática definida a partir desse recurso botânico foi a fotossíntese.

O grupo estruturou como objetivos da aula a importância da fotossíntese, com enfoque em como ocorre nos vegetais o processo de transformação de elementos inorgânicos em compostos orgânicos para a sua manutenção. Sobre o escopo da aula, decidiram abordar os seguintes 
conteúdos botânicos: a morfologia externa da planta, absorção dos nutrientes do solo, condução e transformação e captação da energia luminosa, gás carbônico e sua transformação.

A organização da aula foi montada em cinco etapas: a) estrutura da cadeia alimentar vegetais enquanto produtores; b) produção de alimentos através da fotossíntese; c) nutrição orgânica das plantas; d) partes da planta responsáveis pela absorção de nutrientes inorgânicos (raízes), luz e gás carbônico (folhas), e condução dos nutrientes e metabólitos (caule); e) fatores limitantes para a fotossíntese.

A abordagem foi definida com base no resgate de conhecimentos ecológicos dos estudantes, principalmente sobre cadeia alimentar e transferência de energia. A interatividade estaria embasada em questionamentos sobre o que é importante para a manutenção da vida de todo ser vivo. A aplicação desse conhecimento no mundo real foi destacado como sendo relativo à preservação das plantas para manutenção da vida no planeta.

Para o desenvolvimento da aula o grupo propôs que os estudantes seriam estimulados a visualizar e/ou tocar no material vegetal.

A proposta embora traga algumas possibilidades de discussão sobre o papel ecológico das plantas para a manutenção da vida na Terra, destaca uma abordagem da fotossíntese que segue aspectos clássicos, muito difundidos no livro didático, com uma sequencia ordenada de conteúdos para explicar o fenômeno. Apesar de colocarem que o desenvolvimento da aula seria através da visualização e toque do material disponível nessa estação, não houve uma articulação de ideias no sentido de planejar como a partir das plantas e plântulas vivas seria possível a abordagem do processo de fotossíntese.

Pensamos que o material in natura não se mostrou suficientemente provocador de sentidos/emoções nos futuros professores a ponto de gerar um efeito criativo para além do tradicional, daquilo com o qual eles já tiveram contato, seja na educação básica como ao longo da graduação.

Silva (2008) destaca que o ensino de Botânica é, em sua grande parte, feito por meio de listas de nomes científicos e de palavras totalmente isoladas da realidade, usadas para definir conceitos que possivelmente nem ao menos podem ser compreendidos pelos alunos e pelos professores.

Isso nos leva a questionar se o fenômeno da fotossíntese não pode ser um desses conceitos mal compreendido pelos licenciandos mas que, por fazer parte de uma séria de conteúdos que necessariamente devem configurar o currículo do Ensino Médio foi destacado na proposta didática, mas sem uma ampliação do mesmo para a realidade do estudante, visto que provavelmente nem o próprio futuro professor o compreenda de forma plena. 


\section{Estação 2 (Recortes de revistas)}

A temática definida a partir do recurso botânico disponível foi a dispersão de sementes.

O grupo estruturou como objetivos da aula a conceituação de dispersão de sementes e os diferentes tipos, além da importância da dispersão. Sobre o escopo da aula, decidiram abordar os seguintes conteúdos botânicos: conceituar dispersão de sementes, qualificar os diferentes tipos de dispersão a partir do tipo de fruto ou semente e destacar a importância da dispersão de sementes para a planta e para o ambiente, relacionando-a com a extinção de espécies.

A abordagem foi definida com a apresentação de figuras de interações ecológicas envolvendo a dispersão de sementes, discussão com os estudantes tendo como base exemplos do cotidiano (humanos, formigas, aves, água, vento, morcego) e apresentação de um vídeo sobre um professor indígena e uma cutia (http://www.videonasaldeias.org.br). A interatividade seria embasada em questionamentos e indagações para a construção de conceitos sobre dispersão. Não explicitaram a aplicação desse conhecimento no mundo real.

Para o desenvolvimento da aula o grupo propôs que os estudantes seriam orientados a partir dos exemplos das figuras e discussão conjunta a construir conceitos sobre dispersão e compará-los com definições do livro didático e do dicionário, sendo que posteriormente o vídeo seria exibido.

O grupo tomou os recortes de revista como dispositivo, entendido como um conjunto de estratégias de relações de força que condicionam certos tipos de saber e por ele são condicionados (FOUCAULT, 1977 apud AGAMBEN, 2009, p. 28). Isso porque o grupo pensou os recortes de revista para o desenvolvimento da temática onde o conhecimento botânico seria discutido com os estudantes também por meio de provocações (um filme, as imagens, o livro didático, o dicionário). Embora sem nenhuma informação sobre como esse conhecimento seria aplicado no mundo real, a abordagem do tópico interação entre os animais e as plantas no processo de especiação de forma a destacar situações do cotidiano, vivenciadas pelos estudantes, demonstra que o grupo foi provocado pelos recortes de revista na medida em que trouxe dinamicidade à proposta didática.

Para Silva e Moraes (2011), o professor pode utilizar metodologias simples, mas que possibilitam a participação efetiva do educando. Foi o que o grupo propôs nesse caso, uma vez que a partir de dispositivos simples levariam os estudantes à discussão da temática da dispersão.

\section{Estação 3 (Xiloteca)}

A temática definida a partir do recurso botânico disponível foi a relação árvore-homem.

O grupo estruturou como objetivos da aula relacionar as estruturas presentes na madeira e suas funções, evidenciar o papel da madeira para a árvore e para o homem, e as estruturas 
microscópicas que compõem a madeira. Decidiram abordar os seguintes conteúdos botânicos: relação da madeira com o cotidiano dos estudantes, desmatamento e compra ilegal da madeira, xilema e sua função.

A abordagem foi estruturada partindo-se de uma sugestão de contemplação das árvores no entorno da escola e posterior discussão com os estudantes sobre desmatamento, compra ilegal de madeira e fiscalização/conscientização, a partir de reportagens disponíveis na Internet. Em outro momento, os estudantes seriam estimulados a manusear lupas para observação direta de pedaços de madeira e detalhamento sobre o xilema, sua função na planta e relação com o aquecimento global e desmatamento.

Para o desenvolvimento da aula o grupo propôs que os estudantes deveriam visualizar e/ou tocar no material vegetal e ter acesso a diferentes recursos como atlas, vídeos e textos diversos.

O grupo partiu de uma proposta de contemplação do entorno, que é uma estratégia de interatividade (WAGENSBERG, 2000), no sentido de promover sensibilizações nos estudantes a partir do contato com o meio.

Embora pareça algo corriqueiro, a visita a um espaço com árvores não é trivial. Matarezi (2001) afirma que apesar de todos os benefícios que podem ser gerados pelas atividades ao ar livre, observa-se que este contato com a natureza é muito restrito, visto que a maioria da população mundial vive nas grandes cidades e metrópoles, privada de um contato direto e permanente com a natureza.

Outro aspecto interessante na proposta do grupo foi a abordagem de questões sócioambientais sobre o desmatamento e o tráfico de madeira, trazendo assim uma problemática contemporânea associada ao conhecimento botânico.

\section{Estação 4 (Jarro de flores)}

A temática definida a partir do recurso botânico disponível foi a reprodução relacionada aos grandes grupos vegetais.

O grupo estruturou como objetivos da aula reconhecer os grupos vegetais pelas diferenças morfológicas e associar a evolução, adaptações e estruturas reprodutivas em função dos diferentes ciclos de vida.

A abordagem foi estruturada tendo como base vários questionamentos para os estudantes sobre as plantas que eles visualizam no cotidiano e através de desenhos sobre as estruturas reprodutivas. 
Para o desenvolvimento da aula o grupo propôs que os estudantes deveriam ter acesso a diferentes recursos como esquemas, gravuras e vídeos sobre o ciclo de vida de briófitas, pteridófitas, gimnospermas e angiospermas.

O grupo estruturou a proposta didática tendo como mote questionamentos sobre as plantas que os estudantes vêem no dia a dia. Embora haja uma iniciativa de partir de algo que faz parte da vida do estudante, o jarro de flores não foi tomado como dispositivo. Os recursos sugeridos focam o ciclo de vida de forma desarticulada com o material vivo disposto na estação. Não houve uma articulação entre os desenhos das estruturas reprodutivas e o ciclo de vida dos vegetais destacados, o que reforça a visão do ensino de botânica ser ilustrativo e enciclopédico, tão bem apontado por Towata e colaboradores (2010).

\section{Composições botânicas}

As propostas didáticas estruturadas pelos grupos de licenciandos nos levam a perguntar por que alguns se deixam provocar e outros fazem de forma técnica, somente para cumprir protocolos?

Os dispositivos por si só, colocados nas estações, não são suficientes para aguçar a criatividade em todos os futuros professores. A interação no grupo e a disposição para compor para além do tradicional são fatores importantes que precisam ser investigados no sentido de compreender aquilo que de fato provoca os licenciandos quando da elaboração de uma proposta didática.

Talvez pudéssemos pensar em autonomia como a capacidade de desenvolver o conhecimento adquirido com criatividade?

Será que isso não estaria relacionado com a falta de vivência? No desafio de ser provocado a pensar de formas outras para além daquilo que nos é repassado em formatos tradicionais ao longo da nossa escolarização?

Até que ponto o receio de ousar, da independência, de tomarem para si a responsabilidade de organizarem e decidirem como fazer e como desenvolver um conteúdo os deixam limitados para sair do comum?

Essa nossa provocação tomou-os de susto. E talvez o inesperado seja um caminho desafiador à criatividade e à constituição da autonomia do futuro professor.

Pensamos a proposta com elementos vegetais numa composição onde foi possível, para os grupos que se dispuseram à provocação, relacionar o conteúdo botânico com o cotidiano, com a vida dos estudantes, com questões atuais de cunho social e ambiental. Onde a planta em si, foi apenas um dispositivo para a imaginação.

218 DOI: Em andamento.

R. Bras. de Ensino de C\&T 


\section{Referências}

ABBAGNANO, Nicola. Dicionário de filosofia. 5 ed. rev. e ampl. São Paulo: Martins Fontes, 2007.

AGAMBEN, Giorgio. O que é o contemporâneo? E outros ensaios. Tradução: Vinicius Nicastro Honesko. Chapecó: Argos, 2009.

ALENCAR, Eunice Soriano de. O estímulo à criatividade em programas de pós-graduação segundo seus estudantes. Psicologia: Reflexão e Crítica, v. 15, n. 1, p. 63-70, 2002

BARDIN, Laurence. Análise de conteúdo. Trad. Luís Antero e Augusto Pinheiro. Lisboa: Edições 70, 1977.

CAJAL, Irene. A interação de sala de aula: como o professor reage às falas iniciadas pelos alunos? In: COX, Maria I. P.; ASIS-PETERSON, Ana A. (orgs.). Cenas de sala de aula. Campinas: Mercado de Letras, p. 125-159, 2003.

FALCÃO, Douglas; ALVES, Fátima; KAPRAS, Sônia; COLINVAUX, Dominique. Museus de ciências, aprendizagem e modelos mentais: identificando relações. In: GOUVÊA, G.; MARANDINO, M.; LEAL, M. C. (Org.). Educação e Museu: a construção social do caráter educativo dos museus de ciências. Rio de Janeiro: Access, p. 185-206, 2003.

FALK, John Howard. Identity and the museum visitor experience. Walnut Creek: Left Coeast Press, 2009.

FERREIRA, Gustavo Lopes. A Interatividade nos Museus de Ciências: o processo de criação de um artefato museal. 2014, 163 p. Dissertação de Mestrado (Programa de Pós graduação em Educação). Faculdade de Educação, Universidade Federal de Uberlândia, Uberlândia, 2014.

GARCIA, Marisa Ferreira Fontes. Repensando a Botânica. In: ENCONTRO PERSPECTIVAS DO ENSINO DE BIOLOGIA, 5., 2000, São Paulo. Coletânea do 70 Encontro Perspectivas do Ensino de Biologia, São Paulo: Faculdade de Educação da Universidade de São Paulo, 2000.

KINOSHITA, Luiza Sumiko, TORRES, Roseli Buzanelli, TAMASHIRO, Jorge Yoshio, FORNI-MARTINS, Eliana Regina. A Botânica no ensino básico: relatos de uma experiência transformadora. RiMa, São Carlos, 2006.

LÜDKE, Menga; ANDRÉ, Marli. Pesquisa em educação: abordagens qualitativas. São Paulo: EPU, 1986.

MATAREZI, José. Trilha da vida: re-descobrindo a natureza com os sentidos. Revista Eletrônica do Mestrado em Educação Ambiental, p.1-14, 2001.

MORAES, Roque. Análise de conteúdo. Revista Educação, Porto Alegre, v. 22, p.7-32, 1999.

MOURÃO, Renata Fernandes; MARTínEZ, Albertina Mitjáns. A criatividade do professor: a relação

R. B. E. C. T., vol 8, núm. 4, set-dez.2015 ISSN - 1982-873X

DOI: Em andamento. 
entre o sentido subjetivo da criatividade e a pedagogia de projetos. Revista Semestral da Associação Brasileira de Psicologia Escolar e Educacional (ABRAPEE), v. 10, n. 2, p. 263-272, 2006. NASCIMENTO, Silvania Sousa do; VENTURA, Paulo César Santos. Mutações na construção dos museus de ciências. Pro-posições, v. 12, n. 1 (34), p.126-138, 2001.

OLIVEIRA, Eliana de; ENS, Romilda Teodora; FREIRE Andrade, Daniela; MUSSIS, Carlo Ralph de. Análise de conteúdo e pesquisa na área da educação. Revista Diálogo Educacional. Metodologia, Política e Filosofia da Educação, PUCPR, v. 4, n. 9, p. 51-62, 2003.

SCHÖN, Donald. Formar professores como profissionais reflexivos. In: NÓVOA, A. (Org.). Os professores e a sua formação. 3a. Edição. Lisboa: Dom Quixote, p. 79-91, 1997.

SILVA, Audilia Borges Vitorina; MORAES, Moemy Gomes. Jogos pedagógicos como estratégia no ensino de morfologia vegetal]. Enciclopédia Biosfera, Centro Científico Conhecer - Goiânia, v.7, n.13, p. 1642-1652, 2011.

SILVA, Patrícia Gomes Pinheiro da. $O$ ensino da Botânica no nível fundamental: um enfoque nos procedimentos metodológicos. Tese (Doutorado em Educação Para a Ciência) - Universidade Estadual Paulista Júlio de Mesquita Filho, 2008.

STUDART, Denise . Museus e famílias: percepções e comportamentos de crianças e seus familiares em exposições para o público infantil. História, Ciências, Saúde - Manguinhos, v.12 (suplemento), p. 55-77, 2005.

TOWATA, Naomi; URSI, Suzana; SANTOS, Déborah Yara Alves Cursino dos. Análise da Percepção de Licenciandos sobre o "ensino de Botânica na educação básica". Revista da SBEnBio, n3, p. 1603-1612, 2010.

WAGENSBERG, Jorge. Principios fundamentales de la museologia científica moderna. Alambique Didáctica de Las Ciencias Experimentales. n. 26, p. 15 - 19, 2000.

Renata Carmo-Oliveira - Instituto de Biologia, Universidade Federal de Uberlândia - Programa de Pós-Graduação em Biologia Vegetal

carmoliveira@ufu.br

Daniela Franco Carvalho - Instituto de Blologia, Universidade Federal de Uberlândia - Programa de Pós-Graduação em Educaçao ( Faculdade de Educação )

danielafcj@gmail.com 